\title{
Preferences of Medical Students for Rural Medical Internships in South Africa: A Discrete Choice Experiment
}

\section{Maria Jose ( $\sim$ jsxmar002@myuct.ac.za )}

University of Cape Town School of Public Health and Family Medicine https://orcid.org/0000-0001-

5116-605X

\section{Amarech Obse}

University of Cape Town School of Public Health and Family Medicine

\section{Mark Zuidgeest}

University of Cape Town Faculty of Engineering and the Built Environment

\section{Olufunke Alaba}

University of Cape Town School of Public Health and Family Medicine

\section{Research}

Keywords: medical students, rural health, careers, decision making, health economics, human resources, incentives, labour market, developing countries, occupational health.

Posted Date: September 3rd, 2020

DOl: https://doi.org/10.21203/rs.3.rs-67845/v1

License: (c) (1) This work is licensed under a Creative Commons Attribution 4.0 International License. Read Full License 
4 Corresponding Author: Dr Maria Jose ${ }^{1} \mathrm{MBChB}, \mathrm{MPH}$

$5 \quad$ Email: jsxmar002@myuct.ac.za Tel: +27836303319

6

Address: Health Economics Unit, School of Public Health and Family Medicine, Faculty of Health

7 Science, University of Cape Town, Anzio Road, Observatory 7925.

8

9 Co-Authors: Dr Amarech Obse ${ }^{1}$ PhD, Prof Mark Zuidgeest ${ }^{2}$ PhD, Dr Olufunke Alaba ${ }^{1}$ PhD

10 1. University of Cape Town, Health Economics Unit, School of Public Health and Family Medicine,

11 Faculty of Health Science, Anzio Road, Observatory, 7925

12 2. University of Cape Town, Department of Civil Engineering, Faculty of Engineering \& the Built Environment, Rondebosch, 7701

14

15

16

17

18

19

20

21

22 


\section{Abstract}

Background: Globally the proportion of medical doctors to population in rural areas in low- and middle-income countries remains insufficient to address their health care needs. Therefore, it is imperative to design strategies that attract medical doctors to rural areas to reduce health inequalities and achieve universal health coverage. Methods: This study assessed preferences of medical students for rural internships using a discrete choice experiment. Attributes of rural job were identified through literature and focus group discussions. A D-efficient design was generated with 15 choice sets, each with forced binary, unlabelled, rural hospital alternatives. An online survey was conducted, and data analysed using mixed logit models of main effects only and main effects plus interaction terms. Results: Majority of the respondents were females (130/66.33\%) and had urban origin (176/89.80\%). The main effects only model showed advanced practical experience, hospital safety, correctly fitting personal protective equipment, and availability of basic resources as the most important attributes influencing take up of rural internship, respectively. Respondents were willing to pay ZAR 2645.92 monthly (95\%Cl: $1345.90 ; 3945.94)$ to gain advanced practical experience (equivalent to $66.15 \%$ of current rural allowance). In contrast, increases in rural allowance and the provision of housing were the least important attributes. Based on the interaction model, female respondents and those intending general practise associated higher weight for hospital safety over advanced practical experience. Conclusion: In the context of limited budgets and resource constraints, policy makers and rural health facility managers are advised to prioritise meaningful internship practise environments that offer supervised learning environment, safety from physical and occupational hazards and the provision of basic resources for healthcare system-wide benefits to both staff and rural health facility users alike.

Keywords: medical students, rural health, careers, decision making, health economics, human resources, incentives, labour market, developing countries, occupational health. 
53 The health workforce as a critical building block of a functional health system requires the availability,

54 accessibility, acceptability, and quality of health workers to determine the level of health service coverage and attainment of the highest possible standard of health $(1,2)$. The move towards universal health coverage cannot be realized without motivated and empowered health workers with required competencies, equitably distributed to provide needed services of good quality to the population (3). The Demographic and Health Survey revealed that many countries that accelerated the move towards universal health coverage "have left the poor and rural population behind"(1). The struggle for health equity is faced by countries globally, with the delivery of healthcare to those living in remote and rural areas identified as a pressing challenge (4). The lack of adequate skilled personnel in rural areas has been attributed as the top limiting factor to the scale up of health interventions such as life-saving anti-retroviral treatment and the improvement of maternal and child-health outcomes (5).

64

Rural medical practice is often seen to be challenging due to social and cultural isolation, lack of infrastructure and transport, electricity, telecommunications and restricted access to goods and services (6). The South African National Department of Health's (DOH) strategies for rural doctor recruitment includes recruiting rural-origin students to be trained in Cuba on condition of fixed-term mandatory rural service and the provision of on-site housing which is both expensive and timeconsuming to maintain (7). South African medical doctors are trained in undergraduate medical schools (either in South Africa or Cuba), followed by a two-year compulsory internship at an approved government hospital and additional one-year mandatory community service before they can be certified for independent practice (7). 
in SA was only 9.1 (9). Only $2.9 \%$ of doctors in the SA public sector practise medicine at rural facilities where an estimated $33 \%$ of the population live $(10,11)$. The doctor shortage is both an absolute as well as relative issue, as there is unequal division of doctors along public-private lines, provincial lines, ruralurban lines, poor-wealthy lines and state dependant-medically insured lines (12). The overall distribution of public sector post-internship medical posts are approximately $75 \%$ urban, $25 \%$ rural (13).

82 Despite a desperate need for health workers, in 2003, there was 31\% vacancy rate in the SA public health sector (5). In 2010, there were 10,860 unfilled public sector medical practitioner vacancies, with

the rural province of Limpopo contributing to $46.5 \%$ of these unfilled posts compared to the urbanised province of Gauteng which shared only $10.2 \%$ of the total unfilled posts (14).

The first five years of practice after graduation as a medical doctor are critical for retention in practising medicine (15). This is further illustrated by SA studies of public sector doctors which found that between $6.6 \%-45 \%$ of newly graduated doctors planned to leave medicine, citing lack of equipment at facilities and unbearable workload as push factors $(16,17)$. A qualitative cross-sectional study showed that medical interns were motivated to choose an internship based on proximity of facility location to family and the fulfilment of their provincial bursary obligations, however, that research was not investigating the preferences for rural facilities specifically $(16) .(18,19)$ Although there is data available to describe health worker's practise location intentions, there is currently a dearth of knowledge on the job preferences of medical students. This study therefore seeks to uncover preferences for rural internship job among final-year medical students at the authors institute.

\section{Methods}

Study Design

The study population was the entire final-year medical students at the authors institute who applied for internship placement in 2019 for commencement of work in 2020 ( N= 224 students, of which 200 
103

104

105

106

107

108

109

110

111

112

113

114

115

116

117

118

119

120

121

122

123

124

125

126

127

SA trained, 24 Cuban trained.) Cuban trained medical students commenced their internship in the latter half of 2019 whereas their SA- trained counterparts commenced internship in January 2020.

\section{Discrete choice experiment}

A discrete choice experiment (DCE) is an attributed-based stated preference method used to elicit preferences for goods or services $(20,21)$. In DCE, respondents are presented with a sequence of hypothetical choice questions described by different attributes and levels to select the most preferred alternatives yielding maximum utility (22-24).

\section{Attribute Identification}

Design of a DCE involves identification of attributes and their levels. Attributes are the characteristics of the goods/services. Attribute levels are the specific values that describe the various features of attributes (25). In this study, job attributes that are relevant to healthcare workers were identified from literature and validated by focus group discussions (FGDs) conducted with the study population. Three FGD sessions were held with a total of 15 medical students representing the gender and provincial distribution of the class. Using the FGD guide, students were probed to discuss their views on working at rural areas and what factors can facilitate take up of an internship job in rural areas. On average, the FGDs took 60 minutes per session. All FGDs were conducted in English and recorded with respondents' consent. The FGDs were transcribed verbatim and thereafter a thematic analysis was conducted to identify common attributes. Based on the literature review and the FGDs, seven final attributes were selected (Table 1). Attributes from literature that were dismissed by FGD participants were: proximity of health facility to children's schools and work opportunities for spouses. Attributes that were identified through the FGDs : Personal protective equipment (PPE) in the form of N95 respirator masks to protect against occupational tuberculosis exposure, practical experience and seniority of supervisor. 
130 Using the selected attributes and levels, Sawtooth Software (Sawtooth Software Inc., Sequim, WA,

131 USA) was used to generate D-efficient choice sets which consist of 15 hypothetical job postings. The 132 choice scenarios were binary with generically named 'Rural Hospital A' and 'Rural Hospital B' alternatives. There was no 'opt-out' option to reflect the mandatory nature of the internship process for accreditation. The DCE questionnaire was piloted with 25 final year medical students from the preceding graduating class. Based on their feedback the attribute "occupational hazard" was specified to include the level 'incorrectly fitting masks', these are prone to air-leaks which undermine their

137 effectiveness (26). The attribute "Practical experience" was reworded to provide clarity and examples

138 for each of its levels. The levels of the attribute 'supervision' are defined based on seniority with

139 'medical officer' the most junior doctor authorised to practise independently, followed by 'registrar'

140 who is a specialist-in-training, finally 'consultant' who is an experienced medical specialist. Rural

141 allowance is presented in local currency, South African Rands (ZAR). The attribute 'rural allowance'

142 base level of ZAR $4,000^{1}$ is based on current SA internship rural allowance at $20 \%$ of monthly base salary of ZAR 20,000 excluding overtime (27). The second level was calculated according to historical wage increases as $8 \%$ increase on the base level (28). The third level is a $20 \%$ increase on the base level suggested by FGD participants. The attributes 'Housing', 'Basic Resources', 'Practical experience', and 'Hospital safety' have two levels each as described in Table 1.

The final DCE questionnaire was administered over a one-month period in February 2019. The questionnaire link was sent to the study population at the authors institute via email. It was anonymous and self-administered on devices (laptop/tablet/mobile). It took on average 20 minutes to complete (Figure 1). All students have access to computers on campus at computer laboratories as well as Wi-Fi access. First author was also in person at class lectures to encourage participation among students and provide refreshments.

\footnotetext{
${ }^{1}$ Exchange rate as at 24 August 2020 ZAR17.02=1USD
} 
The analysis of the DCE responses followed the random utility theory framework in which individuals are assumed to have an indirect utility for choice alternatives and make choices based on their discrimination capabilities (21,29). Given binary choice alternatives of 'Rural Hospital A' and 'Rural Hospital B' as described by the attributes, students choose the alternatives that give them the highest utility. The deterministic part of the utility $\left(V_{j n t}\right)$, which is observable, is defined as a linear function of the job attribute levels and is given by:

$$
\begin{aligned}
\mathrm{V}_{\mathrm{jnt}}=\beta_{0}+\beta_{1} \text { sup_regist }_{\mathrm{nt}}+\beta_{2} \text { sup_consul }_{\mathrm{nt}}+\beta_{3} \text { allowance }_{\mathrm{nt}}+\beta_{4} \text { house_provided }_{\mathrm{nt}} \\
+\beta_{5} \text { reso_avail }_{\mathrm{nt}}+\beta_{6} \text { exp_proced }_{\mathrm{nt}}+\beta_{7} \text { safety_good }_{\mathrm{nt}}+\beta_{8} \text { mask_poor }_{\mathrm{nt}} \\
+\beta_{9} \text { mask_correct }_{\mathrm{nt}}
\end{aligned}
$$

161 Where, the variables are defined in Table 1. The attribute rural allowance is modelled as a continuous

162 variable while the remaining variables were categorical, and effects coded. Thus, $\beta_{3}$ indicates change in utility for a unit change in rural allowance while the coefficients of the categorical variables capture the effect of the presence of the attribute levels on utility. Two mixed logit (MXL) models, based on 500 Halton draws, were estimated assuming a normal distribution in Stata v14; (i) a main effects only model which is a function of job attributes only Model 1 , and (ii) main effects plus interaction of attributes with some respondent characteristics (i.e., gender, career aspiration, and prior rural medicine exposure) to explore differences in the valuation of rural internship attributes by subpopulation Models 2.1-2.6. Willingness to pay (WTP) represents the respondent's preferences for rural health facility attributes in monetary terms. Marginal WTP which indicates how much money a final year medical student is willing to pay to work at a rural health facility with attribute level $(k)$ in comparison to a facility with the reference attribute level $(r)$ is estimated; this is then expressed in ZAR and as a percentage of current rural allowance.

174 Given effects coding, for attributes with two levels, marginal WTP was estimated as 
175

$2 * \beta_{k} /-\beta_{3}$ while for attributes with more than two levels it is calculated as $\beta_{k}-\beta_{r} /-\beta_{3}$; where $k \neq 1$ and $k \neq r$. Delta method is used to estimate the $95 \%$ confidence intervals for the WTP estimates (30).

\section{$\underline{\text { Results }}$}

Table 2 presents the respondents' characteristics. The number of respondents who completed the questionnaire were 193 (86.16\%) of 224 final-year medical students. The mean age of respondents, 24 years $(95 \% \mathrm{Cl} 23.65 ; 23.75)$, is consistent with an undergraduate, 6-year medical degree. The sample's female majority 130 (66.33\%) and the distribution of province of origin are reflective of the institute's admission criteria. Majority of participants came from urban areas 176 (89.80\%), were not married 183 (93.37\%), and did not have child dependants 193 (98.47\%). For respondents who had reported undergraduate exposure to rural medicine, opt-in rural electives 43 (32.09\%) and family medicine rotations 51 (38.06\%) proved most popular. Few respondents were provincial bursary holders 45 (22.96\%) or completed their training in Cuba 7 (3.57\%). One hundred ninety-two (97.96\%) participants intended to complete their internship in SA with the majority opting to specialise (109/55.61\%) instead of entering general practise.

Table 3 illustrates the estimation results of mixed logit model with main effects only and main effects plus interaction terms. Other things constant, a larger mean coefficient translates into a greater relative likelihood of choosing a job alternative. An advanced practical experience was the most valued attribute followed by hospital safety, the provision of correctly sized N95 masks, and availability of basic resources. Importantly, the provision of subsidised doctor's quarter and rural allowance were among the least valued attributes. Respondents also preferred job alternatives with consultant supervisors compared to medical officers. A poorly fitting N95 mask was less preferred than having no mask at all. The standard deviations of the mean coefficients of attributes are 
significant at the $1 \%$ level indicating preference heterogeneity among the respondents in relation to these attributes.

202

Further analysis of the heterogeneity using the main effects plus interaction models shows that;

204

overall, females valued the provision of basic resources, correctly fitted masks and advanced practical experience to a greater extent than their male counterparts. The difference in valuation of hospital safety was more pronounced with females weighing hospital safety by more than double that of the valuation by males. Based on interaction of job attributes and career aspirations (intending to specialise or join general practice), being supervised by a consultant was more important for those who intended to specialise. In comparison, hospital safety and the provision of basic resources had higher valuation by those intending general practice. Considering the interaction of undergraduate rural medicine exposure, respondents without undergraduate rural medicine exposure highly valued the provision of housing and having basic resources available. In contrast, their colleagues who have had rural medicine exposure valued supervision by consultants and hospital safety more. significant Rural Hospital A constant term 0.375 (p-value 0.021). Participant fatigue was ruled to be unlikely by a heteroscedastic conditional logit model which demonstrated the later choices being not significantly different from earlier choices. Respondents valuation for their professional development and safety were quantified; they were willing to pay the equivalent of $66.15 \%$ in current rural allowance to work in a facility with advanced practical experience compared to a facility which only

221 offered limited practical experience, all other things being equal(Table 4).

\section{Discussion}

224 This study found the most influential attributes to a final year medical student when considering a rural internship are: advanced practical experience, safety, and provisions for protection against 
occupational hazard. Advanced practical experience is a natural selling point of rural health facilities

227

228

229

230

231

232

233

234

235

236

237

238

239

240

241

242

243

244

245

246

247

248

249

250 due to being understaffed and situated far from referral hospitals. Therefore, facility managers of rural facilities should publicise to prospective staff the valuable "hands-on" experience they stand to gain.

Sub-group analysis by gender showed the value of hospital safety for female students. This is a genuine concern in the context of rural facilities which are often geographically isolated. This finding supports those of Walker and Gilson (31) who documented the experiences of female SA nurses who were victims of crime at their facilities. An integrated approach is needed that co-ordinates facility management, local law-enforcement, and community structures to provide staff and users of rural health facilities with a peaceful environment to work and recuperate. Investment is needed in providing trained security personnel, access control to various sections of the facility as well as adequate lighting of the facility and surrounding areas to deter crime.

Occupational tuberculosis exposure is a unique attribute identified that has not been studied in other health worker recruitment DCE studies. An individual N95 mask cost approximately ZAR7.76 (32) and are ideally replaced on a daily basis, resulting in a monthly cost of approximately ZAR200 (5\% of current rural allowance) at the time of this study's data collection. Interestingly, a poorly fitting N95 mask was less preferred than having no mask at all, highlighting the priority with which medical students value their health and their understanding that a poorly fitting N95 mask is just as ineffective as having no mask at all. In a survey among SA medical and physiotherapy students they rated themselves at a 4.4 times increased risk of contracting TB compared to the general population (33). In the same study $49 \%$ of students reported no access to $N 95$ respirators at the health facilities where they were training(33). Likewise, access to basic resources such as gloves, syringes and needles was a preference that significantly influenced choices both in overall and sub-group analysis. In rural 
facilities which are situated far from medical supply depots, the budgeting and timely procurement of basic resources is vital for the provision of quality healthcare and achieving positive health outcomes.

253

254 A new threat has emerged necessitating the urgent provision of PPE to healthcare workers. At the 255 time of writing, the COVID-19 pandemic has infected an estimated 55,000 healthcare workers in SA; 256 its rapid spread attributed to the pre-existing shortage of PPE (34). Globally the swift response to roll out protective measures and improve the use of PPE have reduced the infection risk among healthcare workers (35). The resulting increase in demand, has led to rapid price surges with N95 masks trebling in price since the pandemic began (36). Therefore, the recruitment cost-effectiveness of PPE and basic resource provision as argued in this study, pre COVID-19, may no longer be tenable. The authors do however remain committed to the continued protection of healthcare workers as an immediate and long-term health priority.

The preference of medical students for consultant supervision places rural facilities at a disadvantage as they are often manned by junior staff. This lack of senior staff may deter graduates, intent on specialising, from working at rural facilities. Conversely, rural facilities that have consultants should provide them with the responsibility to supervise intern doctors as this is a noted drawcard. This finding supports existing literature that SA doctors at rural facilities receiving supervision from seniors reported greater levels of job satisfaction and patient care (37).

271 The popularity of rural allowance and housing provision as a recruitment strategy is thought to be due 272 to its ability to offset travel expenses, thereby lowering the living expenses associated with living in a rural area (37-44). This study however, showed that both rural allowance and housing provision were less important to the study medical students than the other attributes investigated. This supports the 
275 findings of Vujicic et al.(19) who denounced the cost-effectiveness of housing provision as a recruitment strategy in Vietnam. Although higher wages are associated with lower rates of worker

277 attrition, this relationship is inelastic at higher salary levels (as in the case of SA doctors), in which instance other job attributes become a more important influence (45). Pending further research, the DOH should reconsider the implementation of its rural allowance policy for doctors as systematic alternatives, which have been mentioned above, may prove to be impactful and cost-effective in the long-term.

282

The sub-population analysis further highlight heterogeneity in preference of these job attributes by gender, career aspiration, and rural medicine exposure. The finding that female medical students were marginally more sensitive to rural allowance and housing provision is supported by studies in Burkina Faso and Indonesia which found that females were twice more likely to choose a job offer with free housing and were more sensitive to the recruitment effect of rural allowance compared to their male counterparts respectively $(42,46)$.

Career intentions of medical students has been studied in qualitative and quantitative studies career intention with rural health facility attribute preference. This result provides insight into how rural health facilities can offer graduates what they are looking for based on their career aspirations. For the graduate who intends to specialise, rural health facilities can provide the advance practical skills they seek to learn. For those who prefer general practise, a rural facility's safety and resource track record is more influential.

Medical students with rural medicine exposure valued hospital safety highly reflecting the safety concerns they may have encountered personally or heard about during their time at the rural facility. 
301

\section{Conclusion}

314

so than their rural-exposed colleagues contrasts with existing literature (49). This could be due to rural-exposed students feeling more confident to organise their own accommodation

Given the hypothetical nature of the experiment and use of forced choice scenarios overestimation of parameters is a possibility. Despite the alternatives being unlabelled, students chose the alternative that appeared on the left side of their screen more often implying a degree of bias in their choices. The small sample size limits the generalisability of results to all (prospective) medical doctors in the country. It is argued that discrete choice experiment results should be validated by revealed preference data by conducting policy experiments (39). In reality minimal information is available about the attributes of a facility, leading job-seekers to base their decisions on rumours of facility reputation therefore, Robyn et al. (50) encourage greater transparency regarding job listings,.

\section{In the context of limited budgets and resource constraints, policy makers and rural health facility} managers are advised to pay heed to the implications of this study's findings to assist in prioritysetting targeted recruitment initiatives to attract underrepresented medical graduates especially females and those with intention to remain in general practise through transparent and informative rural facility descriptions. This discrete choice experiment identified the range of preferences for rural health facility attributes valued by a diverse sample of final-year medical students at a public university. The authors are confident that the results are representative for SA trained- medical graduates' expectations for a meaningful rural internship placement experience, one that would offer them a supervised learning environment, safety from physical and occupational hazards and the provision of basic resources to complete their clinical responsibilities. It is hoped that these costeffective facility-based incentives would have healthcare system-wide benefits to both staff and rural health facility users alike. 
327 South African National Department of Health's (DOH)

328 South Africa (SA)

329 Discrete choice experiment (DCE)

330 Focus group discussions (FGDs)

331 South African Rands (ZAR)

332 Willingness to pay (WTP)

333 Personal protective equipment (PPE)

334

335

336

337

338

339

340

341

342

343

344

345 
347

348

349

$\underline{\text { Declarations }}$

350

Funding: This study received no external funding and was self-funded by the corresponding Author.

351

The research team would like to acknowledge Sawtooth Software for the provision of access to

352

Lighthouse Studio software on an academic grant.

353

354

Data and materials: The datasets used during this study are available from the corresponding author

355 on reasonable request.

356

357 Ethical clearance: In addition to University of Cape Town Human Research Ethics Committee approval, 358 the study was approved by the University of Cape Town Student Affairs Departments to conduct research involving students enrolled at the University.

360

361 Author's contributions: OA contributed to study proposal, MJ conducted the data collection, AO and MZ contributed to data modelling and analysis. All authors read and approved the final manuscript."

363 Acknowledgments: The research team would like to acknowledge Sawtooth Software for the

364 provision of access to Lighthouse Studio software on an academic grant.

365 Conflicts of Interests: The authors declare no conflicts of interest.

366

367 
370 1. Campbell J, Dussault G, Buchan J, Pozo-Martin F, Guerra Arias M, Leone C, et al. A universal truth: no health without a workforce. Forum Report: Third Global Forum on Human Resources for Health. Recife, Brazil; 2013.

2. World Health Organization. Everybody's business: strengthening health systems to improve health outcomes: WHO's framework for action. Geneva; 2007.

3. World Health Organization. Global strategy on human resources for health: workforce 2030. Geneva; 2016.

4. World Health Organization. Increasing access to health workers in remote and rural areas thrugh improved retention. 2010.

379 5. Schneider H, Blaauw D, Gilson L, Chabikuli N, Goudge J. Health systems and access to antiretroviral drugs for HIV in Southern Africa: service delivery and human resources challenges. Reproductive health matters. 2006 May 1;14(27):12-23.

6. Lagarde M, Blaauw D. Journal of Economic Behavior \& Organization Pro-social preferences and self-selection into jobs : Evidence from South African nurses. J Econ Behav Organ. $2014 ; 107: 136-52$

7. Dambisya YM. A review of non-financial incentives for health worker retention in East and Southern Africa. Equinet Discussion Paper. 2007.

8. George G, Quinlan T, Reardon C, Aguilera JF. Where are we short and who are we short of? A review of the human resources for health in South Africa. Health SA Gesondheid (Online). $2012 ; 17(1): 1-7$

9. World Health Organization. Global Health Observatory data repository. Geneva; 2020. 
11. World Bank. Rural population (\% of total population) - South Africa [Internet]. 2019 [cited 2020 Jul 6]. Available from: https://data.worldbank.org/indicator/SP.RUR.TOTL.ZS?locations=ZA

12. van Rensburg HC. South Africa's protracted struggle for equal distribution and equitable access-still not there. Human resources for health. 2014 Dec 1;12(1):26.

13. Reid S. Community service for health professionals: human resources. South African health review. 2002 Jan 1;2002(1):135-60.

14. Department of Health. Human resources for health South Africa: HRH strategy for the health sector 2012/13 - 2016/17. 2011.

15. Boydstun J, Cossman JS. Career expectancy of physicians active in patient care: Evidence from Mississippi. Rural Remote Health. 2016; 16: 3813

16. Mofolo N, Botes J. South African Family Practice An evaluation of factors influencing perceptual experiences and future plans of final-year medical interns in the Free State. S Afr

17. Longmore B, Ronnie L. Human resource management practices in a medical complex in the

18. Rockers PC, Jaskiewicz W, Wurts L, Kruk ME, Mgomella GS, Ntalazi F, et al. Preferences for

19. Vujicic M, Shengelia B, Alfano M, Bui H. Social Science \& Medicine Physician shortages in rural Vietnam : Using a labor market approach to inform policy. Soc Sci Med. 2011;73(7):970-7. 
review of the literature. Health economics.2012;21:145-72.

416

21. Ryan M, Gerard K, Amaya-Amaya M. Discrete choice experiments in a nutshell. InUsing discrete choice experiments to value health and health care 2008 (pp. 13-46). Springer, Dordrecht.

22. Louviere JJ, David HA, Swait JD. Stated Choice Methods: Analysis and Applications. Cambridge University Press; 2000. 1-18 p.

23. Johnson FR, Lancsar E, Marshall D, Kilambi V, Bs BA, Mu A, et al. Constructing Experimental Designs for Discrete-Choice Experiments : Report of the ISPOR Conjoint Analysis Experimental Design Good Research Practices Task Force. 2013;6:3-13.

24. Lancsar E, Louviere J. Conducting discrete choice experiments to inform healthcare decision making: a user's guide. Pharmacoeconomics. 2008;26:661-677.

25. Jaskiewicz W, Deussom R, Wurts L, Mgomella G. Rapid retention survey toolkit: designing evidence-based incentives for health workers. Washington, DC: USAID and CapacityPlus. 2012.

26. Sissolak D, Marais F, Mehtar S. TB infection prevention and control experiences of South African nurses-a phenomenological study. BMC Public Health. 2011 Dec 1;11(1):262.

27. Mburu G, George G. Determining the efficacy of national strategies aimed at addressing the challenges facing health personnel working in rural areas in KwaZulu-Natal, South Africa. African journal of primary health care \& family medicine. 2017;9(1):1-8.

28. South African Medical Association. Public Service Coordinating Bargaining Council (Pscbc) Update on salaries and Conditions of Service In Public Service [Internet]. 2017 [cited 2018 Feb 17]. Available from: https://www.samedical.org/cmsuploader/viewArticle/607

29. McFadden D. Conditional logit analysis of qualitative choice behaviour. In: Zarembka P, editor. Frontiers in Econometrics. New York: Academic Press; 1974. p. 105-42. 
438

439

440

441

442

443

444

445

446

447

448

449

450

451

452

453

454

455

456

457

458

459

460

30. Oehlert GW. A note on the delta method. Am Stat. 1992;46(1):27-9.

31. Walker L, Gilson L. 'We are bitter but we are satisfied': nurses as street-level bureaucrats in South Africa. Soc Sci Med. 2004;59(6):1251-61.

32. Be Safe Paramedical Suppliers. Surgical Mask - N95 (20 pack). [Internet]. [cited 2019 Mar 6]. Available from: https://be-safe.co.za/shop/bio-safety/surgical-mask-n95/

33. Van der Westhuizen HM, Kotze K, Narotam H, Von Delft A, Willems B, Dramowski A. Knowledge, attitudes and practices regarding TB infection control among health science students in a TB-endemic setting. Int J Infect Control. 2015;11(4).

34. Businesstech. South Africa's healthcare workers infected with Covid-19. Businesstech. 2020 Jun 11; Available at https://businesstech.co.za/news/lifestyle/406813/south-africashealthcare-workers-infected-with-covid-19/. Accessed on 24 July 2020.

35. Nienhaus A, Hod R. COVID-19 among Health Workers in Germany and Malaysia. Int J Environ Res Public Health. 2020;17(13):4881.

36. World Health Organization. Shortage of personal protective equipment endangering health workers worldwide. News release 3 Mar 2020. Available at https://www.who.int/newsroom/detail/03-03-2020-shortage-of-personal-protective-equipment-endangering-healthworkers-worldwide.Accessed on 24 July 2020.

37. Kotzee TJ, Couper ID. What interventions do South African qualified doctors think will retain them in rural hospitals of the Limpopo province of South Africa? Rural Remote Heal. 2006. 6:581.

38. Mangham LJ, Hanson K. Employment preferences of public sector nurses in Malawi: results from a discrete choice experiment. Tropical Medicine \& International Health. 2008 Dec;13(12):1433-41. 
461

39. Kruk ME, Johnson JC, Gyakobo M, Agyei-Baffour P, Asabir K, Kotha SR, et al. Rural practice preferences among medical students in Ghana: A discrete choice experiment. Bull World Health Organ. 2010;

40. Kolstad JR. How to make rural jobs more attractive to health workers. Findings from a discrete choice experiment in Tanzania. 2011;211(January 2010):196-211.

41. Ageyi-baffour P, Rominski S, Nakua E, Gyakobo M, Lori JR. Factors that influence midwifery students in Ghana when deciding where to practice : a discrete choice experiment. BMC Med Educ. 2013;13(1):1.

42. Bocoum FY, Koné E, Kouanda S, Yaméogo WME, Bado AR. Which incentive package will retain regionalized health personnel in Burkina Faso : a discrete choice experiment. Hum Resour Health. 2014;12(Suppl 1):S7.

43. Longmore $\mathrm{B}, \mathrm{Chb} \mathrm{MB}$, Ronnie L. Human resource management practices in a medical complex in the Eastern Cape, South Africa : Assessing their impact on the retention of doctors. $2014 ; 104(5): 368-71$.

44. Honda A, Vio F. Incentives for non-physician health professionals to work in the rural and remote areas of Mozambique-a discrete choice experiment for eliciting job preferences. Human resources for health. 2015 Dec 1;13(1):23.

45. McPake B, Scott A, Edoka I. Analyzing markets for health workers: insights from labor and health economics. The World Bank; 2014 Jun 23.

46. Chomitz K, Setiadi G, Azwar A, Ismail N. What do doctors want? Developing incentives for doctors to serve in Indonesia's rural and remote areas. The World Bank; 1999 Nov 30.

47. Stagg P, Greenhill J, Worley PS. A new model to understand the career choice and practice location decisions of medical graduates. Rural Remote Health. 2009;9:12. 
484

485

486

487

488

489

490

491

492

48. El Koussa M, Atun R, Bowser D, Kruk ME. Factors influencing physicians' choice of workplace: systematic review of drivers of attrition and policy interventions to address them. Journal of global health. 2016 Dec;6(2).

49. Vujicic M, Alfano M, Ryan M, Wesseh CS, Brown-Annan J. Policy options to attract nurses to rural Liberia: evidence from a discrete choice experiment. Health, Nutrition and Population (HNP) discussion paper. Washington, DC: World Bank.2010.

50. Robyn PJ, Shroff Z, Zang OR, Kingue S, Djienouassi S, Kouontchou C, et al. Original Article Addressing health workforce distribution concerns : a discrete choice experiment to develop rural retention strategies in Cameroon. Int J Health Policy. 2015;4(3):169-80. 


\section{If these were your only internship options, which would you choose?}

(1 of 15 )

Supervision

Practical experience

Resources

Rural allowance

Hospital Safety

\section{Occupational \\ Hazard \\ Housing}

\begin{tabular}{|c|}
\hline Rural Hospital A \\
\hline Supervised by Medical officer \\
\hline $\begin{array}{l}\text { Limited to filling out forms } \\
\text { and taking bloods }\end{array}$ \\
\hline $\begin{array}{l}\text { Daily stock out of gloves, } \\
\text { syringes and suture packs }\end{array}$ \\
\hline R4000 (current level) \\
\hline $\begin{array}{l}\text { There have been few reports } \\
\text { of theft, hijacking and } \\
\text { protests in and around the } \\
\text { hospital in the past year }\end{array}$ \\
\hline $\begin{array}{c}\text { Correctly sized N95 masks } \\
\text { always available }\end{array}$ \\
\hline $\begin{array}{c}\text { Provided with subsidised } \\
\text { doctors quarters on hospital } \\
\text { premesis }\end{array}$ \\
\hline Select \\
\hline
\end{tabular}

\begin{tabular}{|c|}
\hline Rural Hospital B \\
\hline Supervised by Registrar \\
\hline $\begin{array}{l}\text { Includes filling out forms, take } \\
\text { bloods and doing procedures } \\
\text { e.g. lumbar punctures }\end{array}$ \\
\hline $\begin{array}{c}\text { Gloves,syringes and suture } \\
\text { packs available daily }\end{array}$ \\
\hline R4340 ( $8 \%$ increase) \\
\hline $\begin{array}{l}\text { There is a high level of crime } \\
\text { in and around the hospital } \\
\text { with many reports of theft, } \\
\text { hijacking and protests in the } \\
\text { past year. }\end{array}$ \\
\hline $\begin{array}{c}\text { Poorly fitting N95 masks } \\
\text { always available }\end{array}$ \\
\hline Rent private accomodation \\
\hline Select \\
\hline
\end{tabular}

\section{Back}

Next

Q96

10036

\section{Figure 1}

Example of Discrete Choice Experiment choice set presented to participant. 